\title{
Experimental study of temperatures in characteristic sections of the working zone of a closed two-phase thermosyphon under the condition of a heat removal by external periphery
}

\author{
Atlant Nurpeiis ${ }^{1, *}$, Evgeniya Orlova ${ }^{1}$, and Gennady Mamontov ${ }^{1}$ \\ ${ }^{1}$ National Research Tomsk Polytechnic University, 634050 Tomsk, Russia
}

\begin{abstract}
We present the results of the experimental study of temperature fields in a closed two-phase thermosyphon. Operational modes of a thermosyphon with different heat supply conditions are studied experimentally using setup consisting of the copper case, systems of heat supply and removal in evaporation and condensation zones, and temperature recording facilities. The height of the heat exchanger is $161 \mathrm{~mm}$, thickness of the side walls and bottom wall are $1.5 \mathrm{~mm}$ and $2 \mathrm{~mm}$, respectively, inner diameter is $39 \mathrm{~mm}$. Heat is supplied to the bottom wall by heating element. The heat carrier is distilled water. We obtained thermograms when heat fluxes to the bottom wall of the thermosyphon are $695-2136 \mathrm{~W} / \mathrm{m}^{2}$.
\end{abstract}

\section{Introduction}

Heat removal from the heat-generating parts and modules is the most important thing for successful operation of modern energy-saturated equipment [1-6]. Traditional cooling systems with ventilation and pump installations cannot be always applied because it is often necessary to create additional heat exchange surfaces to remove high heat fluxes. Overheating or failure of auxiliary equipment leads to emergency operation of energysaturated equipment. For this reason, the use of heat-transfer devices independent of electrical power sources is topical. One of such autonomous heat-exchanger is a closed two-phase thermosyphon which can be used to thermostate and thermoregulate different technological processes $[7,8]$. Evaporation and condensation in the heat exchangers under consideration are spatially separated, which makes it possible to transform the heat fluxes by changing the ratio of evaporation and condensation surfaces. However, at present thermosyphons are not widely spread in industry due to the fact that the physics of the joint heat transfer processes and phase transformations in the vapor channel, the heat carrier in the evaporation and condensation zones, the condensate film flowing along the side walls in the thermosyphon has not been sufficiently studied. The known results of a theoretical study of these processes, for example, $[9,10]$, were obtained using complex mathematical models. Solving problems of the type $[9,10]$ is laborious and time consuming. To simplify the same problems of type

*Corresponding author: nurpeiis_atlant@mail.ru 
$[9,10]$, the experimental data on the heat transfer in thermosyphons are not sufficient. Therefore, experimental studies of the temperature fields of thermosyphons are relevant.

The purpose of this work is to study experimentally temperature changes behavior in the characteristic sections of the working zone of the thermosyphon under the condition of a heat removal by external periphery.

\section{Results and discussion}

To conduct experimental studies of the operational modes of thermosyphon with different heat supply conditions, the setup [11] has been developed. It consists of the copper case, systems of heat supply and removal in the evaporation and condensation zones, and temperature recording facilities. The height of the heat exchanger is $161 \mathrm{~mm}$, thickness of the side walls and bottom wall are $1.5 \mathrm{~mm}$ and $2 \mathrm{~mm}$, respectively, inner diameter is $39 \mathrm{~mm}$. Heat is supplied to the bottom wall by heating element. The heat carrier is distilled water. The choice of such a liquid is due to the fact that the distilled water is fire and explosionproof, as well as easily accessible.

Figure 1 presents typical thermograms obtained when the part of thermosyphon cavity is filled with the heat carrier in the range of heat loads from 695 to $2136 \mathrm{~W} / \mathrm{m}^{2}$.

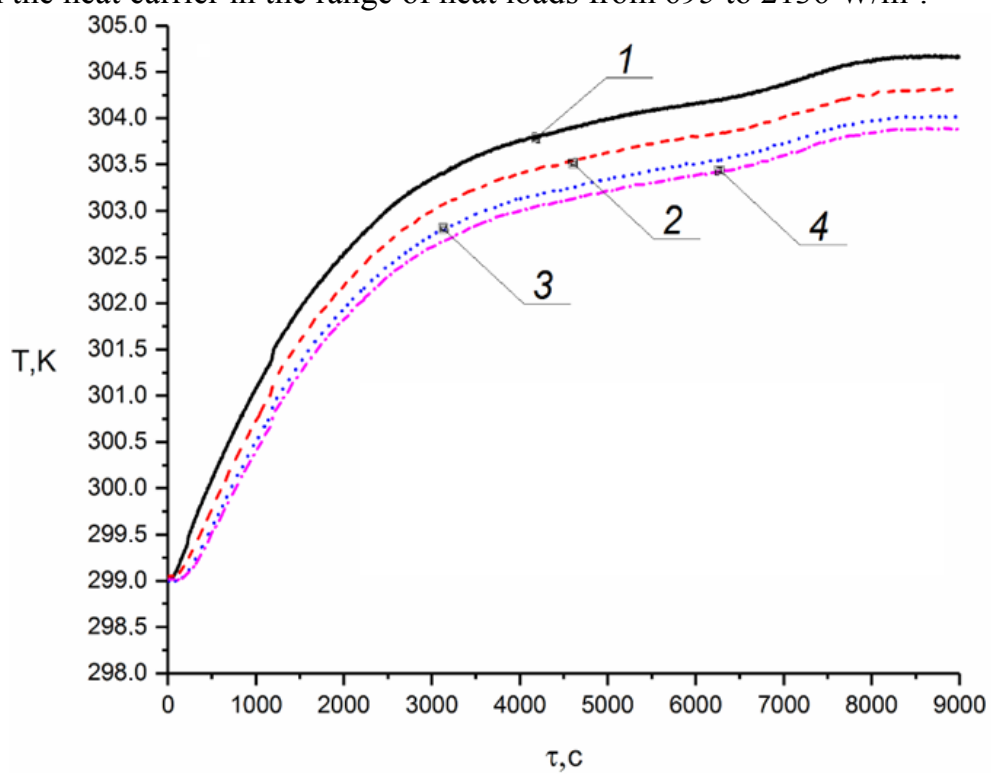

a) 


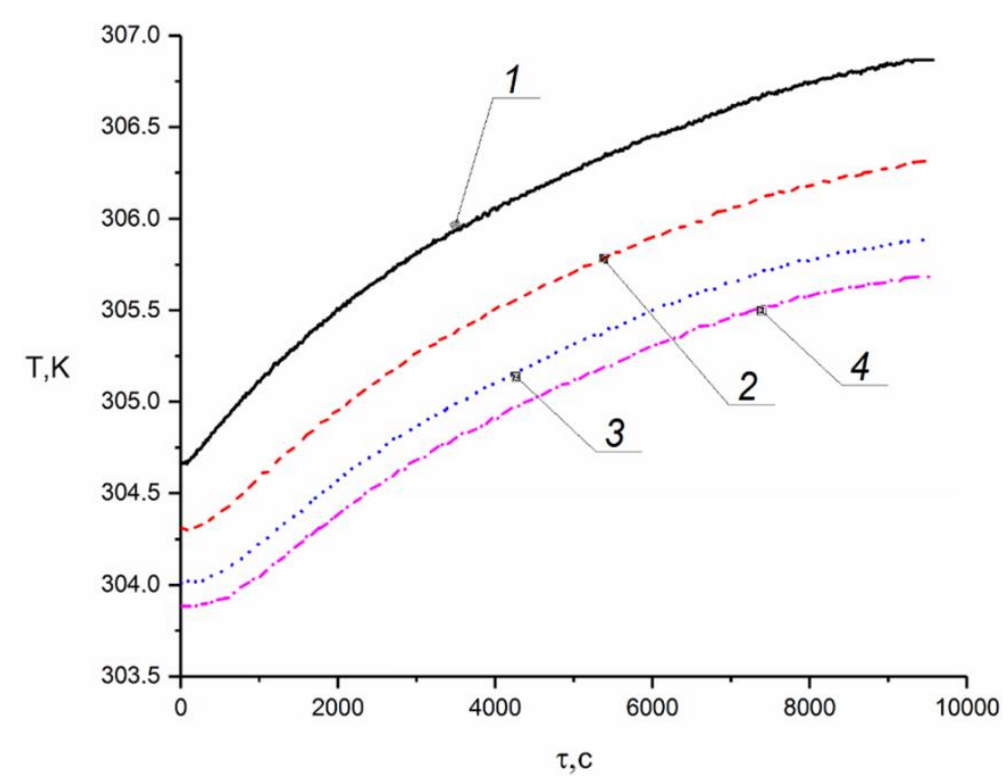

b)

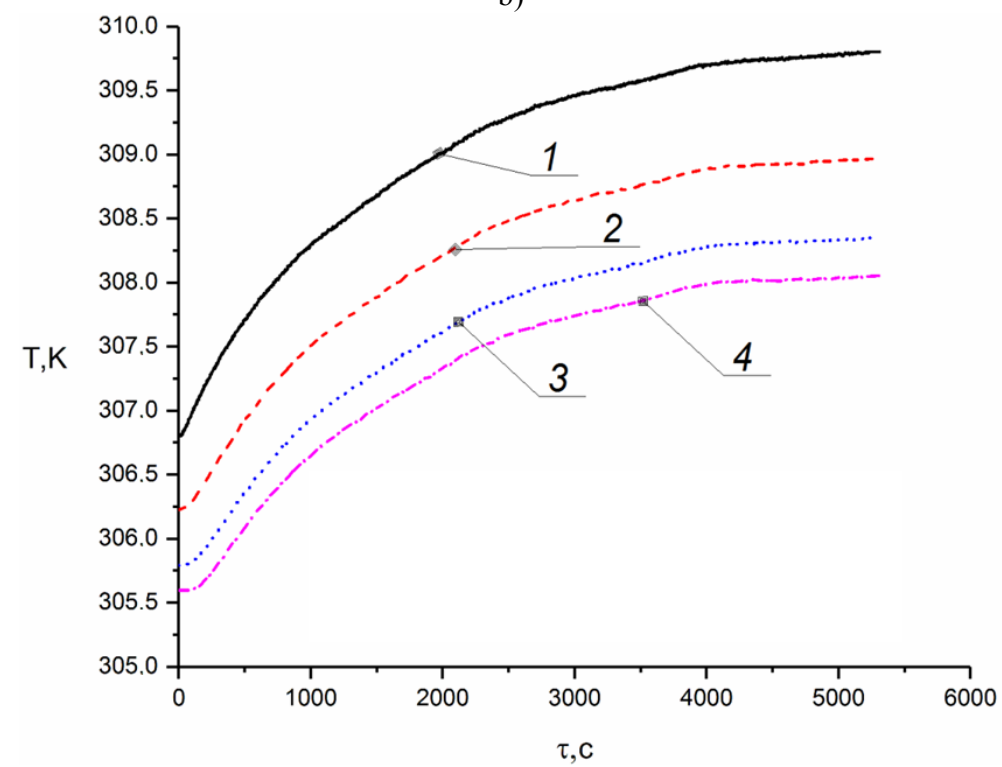

c) 


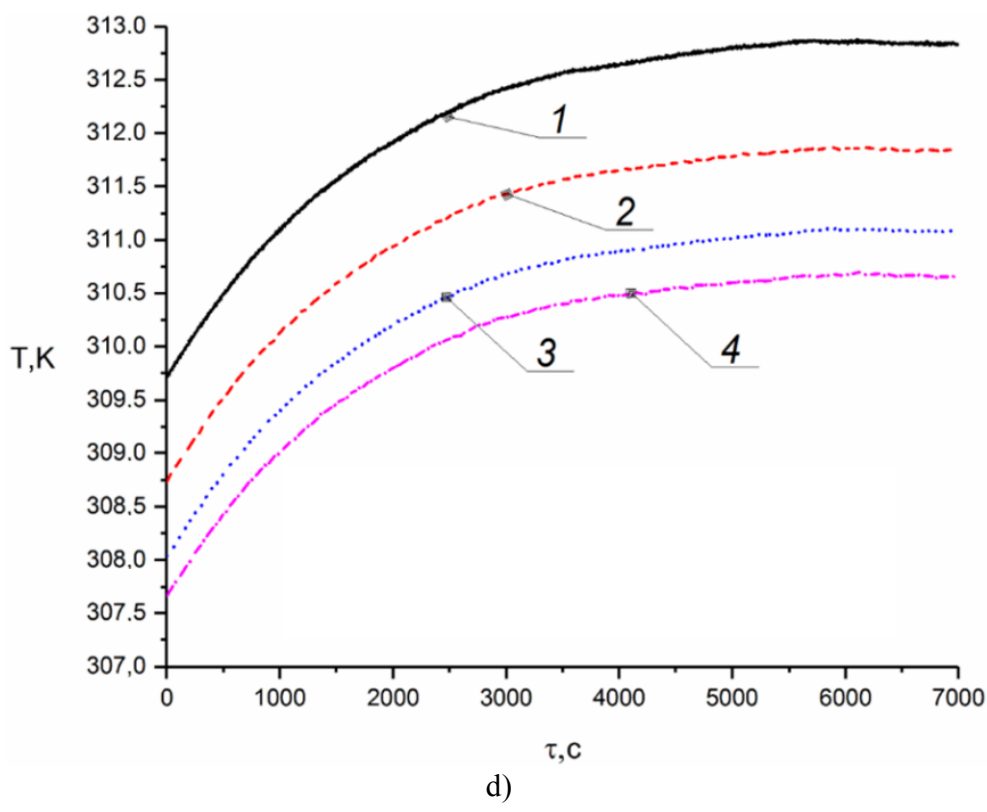

Fig. 1. Time dependences of temperatures in the characteristic points when the filling ratio is equal to $4 \%$ and the heat load is: a) $\mathrm{q}=695 \mathrm{~W} / \mathrm{m}^{2}$, b) $\mathrm{q}=1088 \mathrm{~W} / \mathrm{m}^{2}$, c) $\mathrm{q}=1568 \mathrm{~W} / \mathrm{m}^{2}$, d) $\mathrm{q}=2136 \mathrm{~W} / \mathrm{m}^{2}(1$ is a layer of heat carrier; 2 is a lower boundary of the vapor channel; 3 is a center of the vapor channel; 4 is an upper boundary of the vapor channel).

It can be concluded from Figure 1 that the process of reaching the stationary regime of the thermosyphon temperature fields is quite long in the whole range of the heat fluxes measurement on the heated boundary of the lower wall. Temperature in all points of measurements grow in time during 3000-5000 seconds, herewith the temperature rise depends on intensity of heating. When $\mathrm{q}=695 \mathrm{~W} / \mathrm{m}^{2}$, the temperatures rise by $4.5 \mathrm{~K}$ during 4000 seconds, and when $\mathrm{q}=2136 \mathrm{~W} / \mathrm{m}^{2}$, the rise is $3 \mathrm{~K}$. The most important thing in such case is that the differences in the readings of the thermocouples located at different points of the vapor channel remain practically unchanged. That is, for example, the temperature difference between the evaporation and condensation zones (between the boundaries of these zones) is from $2 \mathrm{~K}$ to $2.3 \mathrm{~K}$ in the range $0<\mathrm{t}<7000$ seconds when $\mathrm{q}=2136 \mathrm{~W} / \mathrm{m}^{2}$. It is worth noting that the non-stationarity of the temperature fields of the inner cavity of the thermosyphon registered in the experiment is not significant and can be neglected in the first approximation in the analysis of the thermosyphon operation. At the same time, it is necessary to clarify that the change of temperature of vapor and condensate in the vapor channel by $2-3 \mathrm{~K}$ during 2.5 hours of work is due to the gradual heating of the thermosyphon walls and cover. In addition, there is a rise in temperature (although insignificant) of water in the area of the bottom cover, respectively, the temperature of evaporation surface and vapor increase.

The reported research was supported by Russian Federation President Grant for state support of the Russian Federation leading scientific schools SS-7538.2016.8 (No.14.Y31.16.7538-SS).

\section{References}

1. V.I. Voronin, P.A. Byshnovich. Electronics industry. 9, (1985). [in russian].

2. S.V. Garimella, V. Singhal, D. Liu, Proceedings of the IEEE, 94, 8 (2006), DOI: 10.1109/JPROC.2006.879801 
3. A.G. Korotkikh, K.V. Slyusarskiy, K.B. Larionov, V.I. Osipov, J. Phys. Conf. Ser., 754, 5 (2016), DOI: 10.1088/1742-6596/754/5/052005

4. S. Yankovsky, A. Tolokolnikov, V. Zaytsev, MATEC Web of Conferences, 110, 01080 (2017), DOI: $10.1051 /$ matecconf/201711001080

5. K.V. Slyusarskiy, K.B. Larionov, V.I. Osipov, S.A. Yankovsky, V.E. Gubin, A.A. Gromov, Fuel, 191, 383 (2017), DOI: 10.1016/j.fuel.2016.11.087

6. J.B. Marcinichen, J.R. Thome, B. Michel, International Journal of Refrigeration, 33, 7 (2010), DOI: 10.1016/j.ijrefrig.2010.06.008

7. M.K. Tiwari, S. Zimmermann, C.S. Sharma, F. Alfieri, A. Renfer, T. Brunschwiler, I. Meijer, B. Michel, D. Poulikakos, 13th IEEE ITHERM Conference, (2012), DOI: 10.1109/ITHERM.2012.6231478

8. A.I. Isakeev, I.G. Kiselev, V.V. Filatov. Effective ways to cool the power semiconductor devices (Energoizdat, Leningrad, 1982) [in russian]

9. G.V. Kuznetsov, A.E. Sitnikov, High Temp., 40, 6 (2002), DOI: 10.1023/A: 1021437502952

10. G.V. Kuznetsov, M.A. Al-Ani, M.A. Sheremet, J. Engin. Thermophys., 20, 2 (2011), DOI: $10.1134 / \mathrm{S} 1810232811020081$

11. D.V. Feoktistov, E.A. Vympin, A.E. Nurpeiis, MATEC Web of Conferences, 72, 01081 (2016), DOI: 10.1051/matecconf/20167201081 